\title{
"We Never was Happy Living Like a Whiteman" : Mental Health Disparities and the Postcolonial Predicament in American Indian Communities
}

\author{
Joseph P. Gone
}

Published online: 29 September 2007

(C) Springer Science+Business Media, LLC 2007

\begin{abstract}
In the context of increasing attention to disparities in health status between U.S. ethnoracial groups, this article examines the dilemma of divergent cultural practices for redressing disparities in mental health status in American Indian communities. Drawing upon an ethnographic interview with a tribal elder from a northern Plains Indian reservation, a prototypical discourse of distress is presented and analyzed as one exemplar of the divergence between the culture of the clinic and the culture of the community. Situated in the context of continuing power asymmetries between tribal nations and the U.S. federal government, the implications of this cultural divergence for the efforts of mental health professionals, practitioners, and policymakers are identified as a predicament that only the conventions and commitments of a robust community psychology have the potential to resolve.
\end{abstract}

Keywords American Indians · Mental health ·

Cultural competence $\cdot$ Ethnopsychology ·

Community psychology

At the dawn of the twenty-first century, America has become increasingly conscious of striking disparities in health status between ethnic and racial groups within its midst, differences that cannot be accounted for by socioeconomic and other healthcare access factors alone (Smedley et al. 2002). These divergences have been attributed to many sources of disparity, including patient-

J. P. Gone $(\bowtie)$

Department of Psychology, University of Michigan, 2239 East

Hall, 530 Church Street, Ann Arbor, MI 48109-1043, USA

e-mail: jgone@umich.edu level, provider-level, and system-level characteristics that intersect and interact within the American healthcare milieu in ways both complex and nuanced (U.S. Department of Health and Human Services 2005). Included in the burgeoning corpus of documented differences in health status by race and ethnicity are difficulties and disorders related specifically to mental health (U.S. Department of Health and Human Services 2001). Virtually all of the current analyses of these disparities reiterate that "culture counts" when it comes to studying, understanding, and (hopefully) redressing these untenable inequalities. Nevertheless, culture-defined here as the public, patterned, and historically-reproduced semiotic practices that both facilitate and constrain the meaningful existence of an affiliated human community (see Gone et al. 1999)—presents certain seemingly intractable dilemmas for service providers in mental health care systems serving minority communities of color in the contemporary United States.

Nowhere are these dilemmas more pronounced than among this nation's remnant and resurgent population of American Indians and Alaska Natives. Comprising some 2.5 million members of roughly 560 federally-recognized tribal nations (U.S. Census Bureau 2002; U.S. Department of the Interior 2002), Native Americans today occupy an utterly distinctive political status in the United States vis-àvis other racial and ethnic minority groups: as citizens of sovereign "domestic, dependent" tribal nations, American Indian and Alaska Native people remain intimately entangled in the policies and practices of the U.S. government (Pevar 2004). This longstanding political relationship - which has vacillated historically from federal military campaigns of extermination to intermittent moments of progressive advocacy-provides the context for assessing mental health disparities among Native Americans. More specifically, the United States currently 
recognizes a moral obligation to provide health care for Native American communities through the branch of the U.S. Public Health Service known as the Indian Health Service (IHS). Mental (or "behavioral") health services are provided in the majority of these IHS-administered or funded reservation and urban health clinics toward the amelioration of disproportionate rates of clinical depression, posttraumatic stress reactions, substance dependence, violence, and suicide (Alcántara and Gone 2007; Beals et al. 2005; Gone 2003, 2004b; Manson and Altschul 2004; Pole et al. in press; U.S. Department of Health and Human Services 2001). Despite this ongoing federal obligation, such services remain chronically underfunded (U.S. Commission on Civil Rights 2004).

The dilemma that culture presents for mental health service providers working with Native American communities originates at the confluence of power and history. Native peoples in the United States are heirs to a shattering legacy of Euro-American colonialism in which both material and ideological war was waged on the cultural practices of indigenous societies. Presently, Native communities endure in fundamentally insecure political, legal, and economic relationships with the U.S. federal government. This tense political context frames the sometimes frantic pursuit of viable postcolonial sources of coherence, connectedness, and continuity for grounding personal and collective meaning-making within contemporary tribal communities (Gone 1999, 2006b, 2007a, in press c), efforts that typically include an explicit commitment to cultural preservation and revitalization. And yet, in the context of this bitter historical legacy and persisting asymmetries in power, what are we to make of the simple fact that the culture of the clinic is not the culture of the community? More specifically, what are professionals, practitioners, and policymakers to do when confronted with substantive cultural divergences in their efforts to redress American Indian mental health disparities? In addressing this query (see also Gone 2004a, 2007b, in press a, in press b; Gone and Alcántara, in press), I first will review a prototypical example of a "discourse of distress" that is increasingly influential within "Indian country," and then I will describe why community psychology is uniquely suited for engaging Native American community well-being in the context of this discourse.

\section{The Postcolonial Predicament: Analyzing a Discourse of Distress in Indian Country}

Several summers ago, I conducted preliminary ethnographic inquiry on a northern Plains reservation that was explicitly concerned with describing the relationships between culture, drinking, and depression in American
Indian community contexts. One result of this fledgling inquiry was an hour-plus interview with "Traveling Thunder," ${ }^{1}$ whose descriptions and explanations of rampant distress on the Fort Belknap Indian reservation in north-central Montana represented a particularly eloquent expression of a shared discourse that is increasingly endorsed by Native American communities throughout the continent.

\section{Contextualizing the Discourse}

A tribal member in his early 50 s at the time of the interview, Traveling Thunder had lived on or near the Fort Belknap reservation throughout most of his life. Traveling Thunder was the firstborn of his parents and was raised primarily by his mother, aunts, and grandmother, where his early years were characterized by material poverty and the routine migrations of family members throughout the region in search of wage labor. Traveling Thunder ended his secondary education during the 12th grade, when he left his Bureau of Indian Affairs (BIA)-administered boarding school to obtain wage work. He later married and relocated to an urban metropolis where the BIA supported his enrollment in trade school. After several years of city life, Traveling Thunder divorced his wife and returned to the reservation, where his principal vocation over the years involved seasonal work as a crew chief combating summer wildfires. Traveling Thunder described drinking alcohol as a young adult to the point where "it became habit forming." For more than a decade, however, he has avoided alcohol and channeled his energies toward stopping the destructive mining of the reservation's southern mountain range by a multinational corporation. In the mid-1990s, the mining operation was forced into bankruptcy following long-overdue investigations by government regulators that validated Traveling Thunder's early public assertions that the operation was poisoning the environment (see also Gone in press b). Since then, following a 25-year hiatus in his formal education, Traveling Thunder has enrolled in a nearby college in pursuit of a Bachelor's degree. Like the vast majority of tribal members at Fort Belknap, Traveling Thunder is a lifelong monolingual English-speaker, and our loosely-structured, open-ended interview was conducted in English. In addition, like some others in his generational cohort at Fort Belknap (Fowler 1987), he identifies as a Native American Traditionalist. I interviewed Traveling

\footnotetext{
${ }^{1}$ I am deeply indebted to this primary respondent who taught me so much during our interview. In considering a variety of options regarding identification, this individual carefully reviewed a draft of this article and requested that I identify him by the name "Traveling Thunder." In addition, he reviewed and approved the biographical description that follows.
} 
Thunder at his home near the mountains for which he had so fervently advocated-our exchange was audio-recorded and later transcribed for analytic purposes.

I recruited Traveling Thunder for participation in the study for several reasons, most of which had nothing to do with firsthand experience or formal expertise regarding "mental health" issues per se. For one, he had been related to several of my other respondents by marriage and helped to round out the range of perspectives within this large extended family. For another, he was interestingly positioned as someone in the developmental transition of becoming an elder. In addition, Traveling Thunder had once contended with the adverse effects of drinking earlier in his life and was prepared now perhaps to reflect on these experiences with the insight born of greater wisdom and maturity. Most importantly, however, was the fact that, of all the individuals I interviewed during that summer, Traveling Thunder was the most active in issues of cultural advocacy and revitalization. Indeed, his grass-roots organizing in response to the ravages of cyanide heap-leach pad gold mining in the nearby Little Rocky Mountains was explicitly grounded in the cultural significance of the mountains for the community and the preservation of sacred sites within them. In short, I was interested in Traveling Thunder's perspective on mental health issues primarily because his expertise lay in "traditional" matters more generally as opposed to direct encounters with the clinicians, therapies, or institutions that comprise the extant "behavioral health" services at Fort Belknap. Finally, I should note that Traveling Thunder generally was committed to a pan-tribal view of cultural and ceremonial exchange-many of the elders he has consulted over the years were not from Fort Belknap, though most resided in tribal communities across the northern Plains.

My focus here on the "discourse of distress" that emerged so clearly from my interview with Traveling Thunder is motivated by its representational force and cultural salience in tribal communities throughout much of Indian country. Of course, the historical backdrop for this discourse is the decimation of Native American communities throughout the era of European contact and subsequent colonialism. Stannard (1992) estimates that 95\% of the indigenous American population died as a result of this "holocaust," and Fowler (1987) documents how European diseases intermittently killed large proportions of the population of Fort Belknap Gros Ventres in epidemic after epidemic throughout much of the eighteenth and nineteenth centuries. Thus, it is not surprising that, in addition to emergence in other interviews at Fort Belknap (Gone 2006c), circulation of this discourse in recognizable form is apparent throughout much of Native North America, whether among tribally-controlled substance abuse treatment centers, organizational alliances of Native people in recovery, medicine people and tribal healers serving their communities, or Native mental health professionals gathering for deliberation and camaraderie. Similarly, a multidisciplinary research literature has attested to the prevalence of this discourse in general form among the indigenous peoples of North America, whether by psychologists (Duran 2006; Duran and Duran 1995), psychiatrists (Kirmayer et al. 2000; Kirmayer et al. 2003), sociologists (Whitbeck et al. 2004), social workers (Tafoya and Del Vecchio 2005; Weaver and Yellow Horse Brave Heart 1999; Yellow Horse Brave Heart 1999), anthropologists (Adelson 2000; O'Nell 1996), or public health specialists (Walters and Simoni 2002). In sum, Traveling Thunder's identification of colonization as the problem and cultural revitalization as the solution for personal and communal disorder and distress would appear to enjoy widespread appeal and endorsement throughout many forums in contemporary Native America (see Waldram 2004, for more extensive consideration). Thus, I present Traveling Thunder's discursively constructed "intentional world" (Shweder 1991) or "local moral world" (Gone et al. 1999; Kleinman 1995) as but one exemplar of a plaintive and potent discourse of distress with broad relevance for those interested in redressing mental health disparities in American Indian communities.

\section{Reviewing the Discourse}

There were numerous facets of my interview with Traveling Thunder that warrant comment and explication, but this article will focus upon the relationship of history and culture to contemporary wellness in Traveling Thunder's words. More specifically, Traveling Thunder structured his observations regarding distress and dysfunction in the community with a description of four historical epochs or eras, the unfolding of which fundamentally hinged upon the Euro-American colonial encounter. Brief attention to each of these historical eras as explicated by Traveling Thunder will prove instructive.

\section{The Era of Precolonial Paradise}

For Traveling Thunder, pre-colonial history consisted of perfect harmony and balance in Native life:

See there was no alcohol in this continent 500 years ago. There was no drugs. There was no problems-no domestic problems, no social problems. Everything was good because everybody lived according to custom and teachings. And there was no jails, no hospitals. There was no prisons, no insane asylums. 
There was none of that stuff because everybody lived according to a strict custom. It would be considered like moral[ity]. Everybody had their morals them days. And...if you didn't listen to the morals of the societal conduct of living,...well, you were kicked out of the tribe. You were banished, they call it, and that was considered a fate worse than death.

And so, according to Traveling Thunder, community life was idyllic once, guided by "morals," structured by "custom," and reinforced not by threat of physical death but by a kind of social death through utter and complete alienation from the community.

\section{The Era of Colonial Incursion}

But then, as Traveling Thunder recounted, Euro-American incursion and, finally, domination changed everything:

You take a group of people that have been living here for thousands and thousands and thousands of years in one way, in one custom, in one traditional way that worked.... Everybody was...happy with it. Nobody didn't want to get rid of it. But when the Whiteman came, they...forced the people, the Indian people, to get rid of their way. Their religious spiritual beliefs. They forced them to trade their economy, which was based on the barter system, and on living off of the land-the wildlife, fish... and herbal medicines. They forced them to change that. And then they not only did that, they annihilated them. Then they turned around and forced their culture on them-their religion, their beliefs, their foreign ways onto them-by taking all the young people out of the homes and putting them away in boarding schools... and forcing the Whiteman's teachings on them. Such as history. They changed history, rewrote history to suit themselves, to justify the bad things they did to the Indian people.... It's genocide... That's what it was: Genocide. Wiping out a whole people so they could benefit.

Note that the first casualty of Euro-American domination-described by Traveling Thunder as the Indian "way" —was the "religious spiritual beliefs" of the people. This prominent emphasis upon spirituality was evident throughout the interview, comprising a rhetoric of indignation in which Traveling Thunder consistently contrasted the sacred and the profane through a series of binary oppositions marking the colonial encounter. For example, Traveling Thunder contrasted the Whiteman's "civilization" on the one hand with the Indian's "destruction" on the other; Native "spiritual ways" with the Christian churches; the "spirit world" with the human world; sacred ceremony with profane alcohol and drugs; historical culture loss with contemporary revitalization; "loss of identity" with cultural pride; and so on. The principal opposition throughout the interview seemed to be what Traveling Thunder referred to as the "old Indian system" versus the "modern Whiteman system" (in which Traveling Thunder clearly distanced himself from "these modern people"). Not surprisingly, he used this contrast to emphasize the moral culpability of the Whiteman for annihilating ancient customs and destroying an idyllic way of life.

\section{The Era of Postcolonial Anomie}

Traveling Thunder then provided an implicit causal account that specified how the ravages of colonialism and "genocide" have effected contemporary disruptions in psychological well-being. More specifically, this account underscores the existential significance of a state of postcolonial anomie: "The number one problem was the loss of their identity." Traveling Thunder elaborated as follows:

Like I say, loss of identity. If you don't know your own true oral history, your true oral traditions and customs and where you come from, and what's supposed to be important to you, well, you're gonna feel empty. You're gonna feel like you don't belong. Cause we don't fit in with the Whiteman's system. We never did and we never will. Indian people never will. Because it's not right. It just ain't in us... We don't come from that. And...we'll never go back to that because it's not our way of life.

The problem then, according to Traveling Thunder, is that Indian people persist in "competing with the Whiteman" in a modern system that is arranged to perpetuate white dominance: "We're in a [horse]race with them, they gave us the worst horse, we'll never catch up to them." The result of this colonial arrangement is rampant demoralization that can lead to serious psychological problems:

So you try to compete with the Whiteman and you can't even do that. You can't do that. You lose in that. So once you lose on all fronts, then you're depressed so you turn to...alcohol and drugs.... It basically boils down to pride. If people ain't proud of who they are, where they come from, and what they're doing, then they're gonna...be doing these things: alcohol, drugs. And once you're into alcohol and drugs...you're gonna probably get into a depression... and you're gonna...not feel worthy of being a human being and you're gonna want to kill yourself. 
The trajectory here is clear: postcolonial anomie produces a futile attempt to compete with whites, which inevitably-owing to inequitable societal arrangementsresults in demoralization, alcohol and drug abuse, depression, and possibly suicide. Thus, Traveling Thunder clearly identified contemporary psychological problems-including alcohol and drug problems - as the existential sequelae of Euro-American colonialism. In essence, then, Traveling Thunder viewed the "modern Whiteman system" as fundamentally pathogenic in regard to Indian mental health and well being.

\section{The Era of Postcolonial Revitalization}

What then, in Traveling Thunder's view, was the course to wellness that successfully navigates the Scylla of anomic despair and the Charybdis of Euro-American assimilation? Some 30 years since the Red Power movement swept through Indian country, his solution was perhaps unsurprising, namely, a return to ancestral "spiritual ways":

And then, after we looked around and realized that...we left something behind..., we started going back to the hills to fast. We started going back to the mountaintops to fast. We started going to the sweat lodges to pray and to sweat. We started going to the elders to learn... Regain... what we were missing. We never was happy, you know, living like a Whiteman.... I would give the credit to the Creator, and to the spirit world, for pitying the people to allow us to get [our ceremonial traditions] back.... To me what that ceremony does is...you put up a sacrifice, an effort... And what you're doing is you're calling on the Creator, the spirit world, and the...grandfather spirits for something. For life, or for good health, or for a...good clean mind. An alcohol and drug free mind. Or you're calling on the spirit world for guidance, you know. Or for survival even. Even survival.

Thus, for Traveling Thunder, the means to a "good, clean mind" - one protected from the "craziness" induced by alcohol and drugs-was a return to the old Indian ceremonial practices. These practices were nearly eradicated by the Whiteman, but fortunately the Creator, "in pitying the people," has afforded the community recent opportunities to retrieve them. Within this movement toward cultural restoration and revitalization-itself born of the Creator's compassion-lies the hope for a renewal of Native wellness and a renascence of Native community. And thus, through the cycle of paradise, incursion, anomie, and revitalization, as cast explicitly in terms of a history of disrupted ceremonial practice, Traveling Thunder fashioned an ethno- (or local) sociology and psychology of plaintive critique and profound expectation in his prototypical discourse of distress.

\section{Extrapolating the Discourse}

What role then might the mental health professional working in the local clinic play? Clearly, Traveling Thunder's indictment of the "modern Whiteman system" as fundamentally pathogenic in regard to Indian mental health would seem to harbor profound implications for the utility and viability of conventional mental health care. I thus inquired of Traveling Thunder what role local service delivery programs might play in support of tribal members struggling with demoralization and related psychological problems. More pointedly, I asked under what conditions he would consider referring his loved ones to the mental health clinic at the local IHS facility. His response was illuminating:

That's kind of like taboo. You know, we don't do that. We never did do that... I guess it's like a war, but they're not using bullets anymore. They're using sophisticated modern technology... [It's] like ethnic cleansing, I guess you could say. They want to wipe us out. Wipe the Indian reservations out so they could join the melting pot of the modern white society. And therefore the Indian problem will be gone forever. That's the way they want [it], and I think they're still doing that. But they're using a more shrewder way than the old style of bullets... If you look at the big picture, you look at your past, your history, where you come from.... and you look at your future where the Whiteman's leading you, I guess you could make a choice. Where do I want to end up? And I guess a lot of people...want to end up looking good to the Whiteman, I guess. Then it'd be a good thing to do: go to white psychiatrists, you know, in the Indian Health Service and say, "Well, go ahead and rid me of my history, my past, and brainwash me forever so I can be like a Whiteman." And I don't know. I guess that'd be a choice each individual will have to make.... I don't like it myself.

And so, for Traveling Thunder, the options were clear. Since the new Indian wars depend upon "brainwashing" rather than bullets, an individual can respond to the worrisome aberrant behavior of a loved one by "putting up" a ceremony and offering prayers ("There's always a spiritual connection that can help them"), or alternatively, by sending them to "white psychiatrists" to rid them of their traditions and "brainwash" them forever. In the context of postcolonial America, then, the effect of conventional 
mental health services provided to tribal communities through Euro-American institutions such as the Indian Health Service was utterly transparent to Traveling Thunder: such services represent an extension of the colonial enterprise.

\section{Appreciating the Discourse}

For those who have dedicated their careers to eradicating disparities in health status, perhaps the most striking aspect of Traveling Thunder's discourse of distress is its reliance upon observations, inferences, and insights, not at the professionally-familiar psychological and biogenetic levels of analysis, but at the sociohistorical and spiritual levels of analysis. For Traveling Thunder, a "good clean mind," "good health," and even "life" itself are gifts of the Creator, Who is moved by "pity" in response to ceremonial "sacrifice" by individuals and communities observing sacred "custom" in the context of ancient "religious spiritual beliefs." As a consequence, mental health problems-including disproportionate rates of anomie, demoralization, depression, substance abuse, and suicideare understood to result directly from the Euro-American colonial encounter by which ritual relationships and responsibilities to powerful other-than-human Persons were disrupted. The obvious remedy for mental health disparities within the context of this "local moral world" is a postcolonial return to individual and communal ceremonial practice, which the Creator Himself has lately rendered possible.

Insofar as this powerful discourse of distress underscores the significance of identity, history, and spirituality, clear cultural divergences appear between the professional principles and practices that guide clinical work in mental health service delivery, and the local explanatory models and idioms of distress characterizing "mental health" within these communities. In the former, the western traditions of dualism, individualism, rationalism, empiricism, and secular modernity prevail, while none of these imported modes of experience necessarily characterizes the latter. In this light, Traveling Thunder's warning that local IHS mental health services involve a subtle form of western cultural proselytization ("brainwashing")independent, of course, of the actual motives and intentions of the clinicians who provide them-seems both plausible and potent. For mental health service providers, too, no matter how sensitive, enlightened, or otherwise "culturally competent," are socialized and enculturated into these professional approaches and practices that diverge substantively from local ways of being in Indian country (Gone and Alcántara 2006; Gone 2003, 2004a, 2007a, $2007 \mathrm{~b}$, in press a, in press b).
I now suspect the implications of Traveling Thunder's warning are fully evident. The culture of the clinic is not the culture of the community. Moreover, substantive divergences in cultural practice persist within the context of asymmetrical power relations. As a result, the neocolonial danger of an implicit but ongoing cultural proselytization of Native peoples by well-intentioned mental health professionals, practitioners, and policymakers remains a formidable consideration in redressing mental health disparities in these communities. In short, clinical intervention is cultural prescription. And yet, Native peoples have already suffered more than their share of "Westis-best" policies, programs, and interventions as a result of their colonial collision with Euro-America. This then is the postcolonial predicament in American Indian communities vis-à-vis mental health disparities: how might therapeutic professionals in their work with Native community members simultaneously (a) avoid the subjugation and displacement of indigenous subjectivities (including, for example, local expressions and expectations regarding emotion, communication, and interpersonal interaction), and yet (b) remain genuinely therapeutic for those individuals who often suffer truly debilitating distress?

\section{A Reciprocal Resolution: Exchanges with Community Psychology}

Traveling Thunder's emphasis upon identity, history, and especially spirituality as foundational for appreciating the mental health concerns of contemporary Native Americans is grounded in an ethos of reciprocity. More specifically, the ancient "religious spiritual beliefs" that Traveling Thunder designated as central to any revitalization effort are routinely expressed through ceremonial practice in which ritual offerings ("a sacrifice, an effort") are made to powerful other-than-human Persons in exchange for gifts of long life, good health, guidance, survival, or "a good, clean mind." This cycle of interpersonal exchange so common to indigenous life on the northern Plains is ordered hierarchically by rank or status vis-à-vis ritual knowledge and Power (Gone, 2006a, 2007a, 2007b, in press b; see also Anderson 2001; Cooper 1957; Flannery 1953; Fowler 1987). Such exchanges are marked by respect and pity, respectively: less powerful persons gift offerings to more powerful persons as expressions of respect, while more powerful persons gift blessings to less powerful persons as expressions of pity (or compassion, accompanied by the obligation to give) (Anderson 2001).

The persons involved in such cycles of reciprocity are both human and other-than human, but among humans the pattern is most characteristically realized in the formal approach of elders by younger community members 
seeking the benefit of relatively advanced knowledge among the aged ("we started going to the elders to learn"; see Gone 2006 c for a contemporary example). In fact, Traveling Thunder described this process explicitly in the interview following a question about how individuals might best overcome alcohol and other drug problems:

Well, I would recommend researching your traditional elders, you know,...no matter where you're from [in Indian country]. Certainly there must be some traditional elders there that carry these sacred teachings on. Usually you just bring a little tobacco, maybe a little gift, depending on how much money you got. You offer it to them and ask them to share information with you. That's the cultural way, traditional way. Give them a little tobacco and a little gift, you know, maybe a little gas money or something. Anything, it don't have to be a whole bunch. But that's the traditional way to ask for guidance and ask for help or ask for knowledge even. You know, you ask for things. You gotta ask or you never get it.

In seeking to resolve the postcolonial predicament described above, I will illustrate briefly with just two examples the mutual benefits that might result from a sustained and reciprocal exchange between intrepid community psychologists and resurgent Native American populations.

What American Indians have to Offer Community Psychologists (for instance)

Since the appearance of Rappaport's (1977) milestone textbook on community psychology nearly three decades ago, several recurring concepts have structured the explorations and activities of community psychologists: ecology, development, diversity, context, collaboration, empowerment, prevention, relativity, and action, to list but a salient few (see Rappaport and Seidman 2000). A definition of the term community, however, continues to elude authoritative consensus within the field (Cronick 2002). Sarason (1974) sought explicitly to anchor the concept within the discipline of psychology by describing the "psychological sense of community" as "the perception of similarity to others, an acknowledged interdependence with others, a willingness to maintain this interdependence by giving to or doing for others what one expects from them, and the feeling that one is part of a larger dependable and stable structure" (p. 157). Given this definition, Sarason explicitly conceded that his construct was inherently imprecise and thus seemingly incompatible with "hard science." Nevertheless, his conviction that a robust sense of community was absolutely essential to human welfare led him later to promote the construct as the sine qua non of the field (Sarason 1986).

Additional theoretical elaboration of the sense of community (McMillan and Chavis 1986) has subsequently motivated operationalization and assessment of this construct by numerous researchers (see Chavis and Pretty 1999 , for their introduction to a recent special issue on the topic), but (to my knowledge) no investigator has ever seriously considered that the sense of community might extend beyond the realm of human affiliation and interaction. And yet, such an extension is precisely what Traveling Thunder would have us realize. More specifically, in matters pertaining to wellness and distress in his community, Traveling Thunder acknowledges that right relations-observed and maintained through ritualbetween human beings and powerful other-than-human Persons are essential for (inclusive) community welfare.

Revisiting Sarason's definitional criteria, then, we can observe that these other-than-human Persons are fundamentally similar to human beings in their expressions of will and intent, principally through thought and language. They depend to some degree upon human beings to realize their wants and desires through the acceptance of respectful gifts (e.g., cultivated tobacco and prepared food) even as they compassionately redistribute well-being to humans (e.g., life, health, and survival). The longstanding nature of this interdependence attests to its solvency ("Everybody was...happy with it. Nobody didn't want to get rid of it."). And its structural dependability and stability remained intact for "thousands and thousands and thousands of years." In fact, according to Traveling Thunder, it was only the Euro-American disruption of these interpersonal relationships-through the violent suppression of "heathen" ritual practices by the federal government and the Christian churches (see Jenkins 2004, for a brief history) - that ultimately led to the epidemic of dysfunction within this community. It stands to reason, then, that the return to right relationships through revitalized ritual practice would be the most appropriate and effective of therapeutic interventions toward the healing of this community. In short, within the context of a renascent relational cosmology (Morrison 2000), aboriginal "culture" is the treatment of choice.

Thus, one contribution that American Indians can offer the field of community psychology is an opportunity to reassess some of the central constructs of our endeavor in light of radically divergent cultural worlds. To the extent that community psychologists remain committed to diversity, collaboration, and empowerment in their inquiry, specificity, nuance, and complication vis-à-vis these constructs in the context of particular community settings should be welcomed. For example, in American 
Indian cultural contexts, the emphasis upon human/otherthan-human relationships and interactions implies a subversion of (or, at least, an incommensurability with) established Western ontologies that divide the cosmos into the human, the natural, and the supernatural realms (Morrison 2000), with attending assumptions (e.g., ontological dissimilarity, mechanistic causality, supernaturalism) and terminology (e.g., "divinity," "spirit," and the "sacred").

But what are community psychologists substantively to make of a psychological sense of community that extends to other-than-human Persons? This question comprises a second, more powerful (and therefore more potentially disruptive) gift that Native communities have to offer the field, namely to challenge community psychologists to articulate more clearly the limits of their commitment to "cultural relativity" (Rappaport 1977). For if one accepts Traveling Thunder's construction of community at face value (in local, emergent, or "emic" terms), then the "scientific" surveillance of this community's psychological sense of itself-confined to an assessment of the (less knowledgeable) responses of its human membership only-would severely circumscribe the validity of such efforts in the eyes of community members. On the other hand, if one assumes within a neo-positivist frame of reference that the other-thanhuman members of this community are not in fact Persons, may not objectively exist, and therefore remain inconsequential to this community's psychological sense of itself (in universal, imposed, or "etic" terms), then this act of privileging "analytically convenient, researcher-designed, a priori, category systems...is willfully neglectful of local contexts and imposes theoretically-rather than locally-derived structures of meaning and relevance" (Rapley and Pretty 1999, p. 698). The result is a potential recapitulation of the injuries of colonialism.

In sum, American Indians confront community psychologists with the ideological tensions that lie within the field's express commitments (e.g., cultural relativity visà-vis robust science) in ways that harbor significant implications for theory, epistemology, and method in community psychology. A more searching and sophisticated consideration of these implications is certainly in order-see, for example, Cronick's (2002) conceptual analysis of community and intersubjectivity, and Rapley and Pretty's (1999) methodological appropriation of conversation analysis for instances of progress in these areas-and enduring partnerships with Native communities will ensure ongoing opportunities for community psychologists both to rethink and refine the fundamental precepts that structure and organize our collective endeavor.
What Community Psychologists have to Offer American Indians (for instance)

Even if the prospect for a recapitulation of the injuries of colonialism challenges the political viability of an uncritical extension of normal science to Indian country, community psychology still retains much promise for American Indian populations. Most importantly, the political commitment of the field's adherents to pursuing "action research" of a collaborative and empowering nature in their work with community partners (Jason, et al. 2003; Rappaport 1990) would seem to be an indispensable strategy for overcoming the bitter colonial legacy that continues to vex contemporary Native peoples. For example, Serrano-Garcì (1990) has traced the formulation of an approach that she and her Puerto Rican colleagues refer to as "intervention within research." This local form of action research was developed in part to redress the colonial legacy through conscientious attention to issues of community participation, empowerment, and accountability through all phases of scholarly investigation. In sum, these approaches-long venerated within community psychology-appear to hold the key to resolving the postcolonial predicament previously described.

If the ideological dangers ("brainwashing") of conventional mental health services for Native American communities result from the inherently normative and prescriptive character of these culturally foreign professional practices, then the primary alternative for ameliorating distress in Indian country-while simultaneously avoiding the ongoing subversion of indigenous subjectivities-is to cultivate and develop therapeutic institutions and activities that actually resonate with local thought and practice. In this regard, I have traced elsewhere the "infinite insufficiency" and "inevitable cultural incongruence" of mental health services in Native American communities and concluded that Indian country requires "a great deal more of the kinds of professional mental health services that do not yet exist" (Gone 2003, p. 221). More specifically, the creation and facilitation of adequate and innovative programs and services that avoid a surreptitious western cultural proselytization will require at least two intersecting elements. First, they will require the expansion of the resources available to Native communities by cultivating underdeveloped service delivery assets, such as traditional healers, natural helpers, tribal college trainees, and grass-roots leaders active in local self-help circles. Second, they will require construction of radically alternative therapeutic institutions and activities that collaboratively engage and competently incorporate local conceptualizations of emotional experience and expression, prevailing communicative norms, cultural notions of disorder and its treatment, and implicit meanings of 
personhood, social relations and spirituality. Together, these strategies will allow us to re-imagine, in local terms, "wellness" and the helping services best tailored to its promotion.

And so, in addition to reinforcing community autonomy and self-determination through genuine collaboration and empowerment, community action research heralds the promise of identifying, cultivating, facilitating, structuring, resourcing, and (perhaps) legitimating any number of alternative, culturally-grounded, community-resonant interventions targeting the disproportionate burden of mental health problems afflicting Native communities. Within this frame of reference, even Traveling Thunder's preference for "a spiritual connection"-an interpersonal interaction structured through ritual that nurtures the wellbeing of community members-is viable as a bona fide therapeutic endeavor worthy of professional support and attention (although only to the extent that community members autonomously welcome such involvement). In sum, if "culture" is widely viewed as the treatment of choice for what ails Indian country, then community psychologists, more so than any other health professionals and interventionists, are uniquely positioned to commence enduring partnerships with American Indian populations toward the locally-valid amelioration of distress and dysfunction that simultaneously averts neo-colonial "West is best" subversions even as it achieves robustly therapeutic outcomes in the community.

\section{Concluding Reflections}

In this article I have attempted to explore the perspective of a single Native American Traditionalist from a northern Plains Indian reservation regarding locally salient "mental health" issues and concerns in an effort to inform the prospects for eradicating mental health disparities in American Indian communities. This analysis explicated a plaintive and potent discourse of distress linking historical dominance by whites to contemporary mental health problems in the context of disrupted ceremonial tradition and spiritual practice. Of particular significance was this respondent's clear and unambiguous characterization of the local mental health service system as complicit in the neocolonial endeavor of western cultural proselytization. The irony here is that most mental health professionals, practitioners, and policymakers who seek to redress mental health disparities in American Indian communities would be appalled at the prospect that their sincere and dedicated efforts to help might be viewed by community members as ongoing cultural eradication. Fortunately, Traveling Thunder himself offered a cautious glimmer of hope, an unelaborated vision for a new kind of interaction:
I would say that if the Indian Health Service was really interested in helping the Indian people, they better learn some culture and some traditions and some respect first before they want to help them. Because...they're liable to do more harm than they are good...if they're gonna force their white ways and white beliefs on [us].

In short, Traveling Thunder observed that respect-the very basis of interpersonal interaction when knowledge is disproportionately distributed-is the prerequisite for a productive partnership between professionals and community members.

If culture truly counts, if culturally competent service delivery genuinely entails the "delivery of services responsive to the cultural concerns of racial and ethnic minority groups, including their languages, histories, traditions, beliefs, and values" (U.S. Department of Health and Human Services 2001, p. 36), how then are mental health professionals to address the substantive divergences in thought and practice that emerge in the cross-cultural clinical encounter? What are they to do in the face of divergent ways of knowing and being that remain fundamentally incommensurate with their own professional approaches and assumptions? I have argued that, for American Indian communities in particular, the postcolonial predicament in which mental health service providers find themselves might be resolved through adoption of the approaches and conventions of community psychology. Owing to the radical alternatives made possible by community psychology's express commitments, Native communities will find unique opportunities through their partnerships with action researchers to pursue therapeutic alternatives well outside the professional mainstream but well within their own local traditions for understanding dysfunction, distress, recovery, and wellness.

If these prescriptive recommendations appear to remove mental health service delivery too far afield from the conventions and constraints of the IHS in particular or the modern U.S. health care system in general, then-if nothing else-mental health service providers are duly obligated to inform American Indian communities of the limitations governing clinician commitments to cultural competency. For even within this prevalent discourse of cultural sensitivity in contemporary U.S. healthcare might be found epistemological tensions, conceptual glosses, and ideological inconsistencies: How should health care providers coherently integrate a politically-responsive cultural relativism and a normatively prescriptive professional expertise? When does the call to "respect" the cultural practices of non-western Others degenerate into convoluted (or even manipulative) efforts by service providers to assert (or even impose) professional expertise upon their less 
powerful charges? And what does the adoption of a western scientific epistemology that supposedly undergirds modern U.S. health care practice imply for local cultural claims that ignore, contradict or reject this dominant way of knowing and its conclusions? Clearly, in the absence of frank and honest disclosure of such perspectives regarding these and related questions to the Native American communities we seek to serve, our professional commitments to cultural competency may well be dismissed as so many meaningless platitudes that continue to reflect the U.S. dominant culture's arrogance and mendacity.

And so, in order to circumvent these dangers and forestall these consequences, I have aspired herein to again convey my respect to Traveling Thunder for his gift of powerful words. As a custodian of so gracious a gift, my obligation is to continue advocating that practitioners and researchers of good will seriously engage the local norms and assumptions of American Indian communities with regard to personhood, distress, and healing. Together, we must collaboratively re-imagine Native American "wellness" in local cultural terms, along with the communitybased partnerships and programs ideally suited to its recovery and circulation.

\section{References}

Adelson, N. (2000). "Being alive well": Health and the politics of Cree well-being. Toronto: University of Toronto.

Alcántara, C., \& Gone, J. P. (2007). Reviewing suicide in Native American communities: Situating risk and protective factors within a transactional-ecological framework. Death Studies, $31,457-477$.

Anderson, J. D. (2001). The four hills of life: Northern Arapaho knowledge and life movement. Lincoln, NE: University of Nebraska.

Beals, J., Manson, S. M., Whitesell, N. R., Spicer, P., Novins, D. K., Mitchell, C. M., for the AI-SUPERPFP Team. (2005). Prevalence of DSM-IV disorders and attendant help-seeking in 2 American Indian reservation populations. Archives of General Psychiatry, 62, 99-108.

Chavis, D. M., \& Pretty, G. M. H. (1999). Sense of community: Advances in measurement and application. Journal of Cотmunity Psychology, 27(6), 635-642.

Cooper, J. M. (1957). The Gros Ventres of Montana: Part IIReligion and ritual (R. Flannery, Ed.). Washington, DC: Catholic University of America.

Cronick, K. (2002). Community, subjectivity, intersubjectivity. American Journal of Community Psychology, 30(4), 529-546.

Duran, E. (2006). Healing the soul wound: Counseling with American Indians and other Native peoples. New York, NY: Teacher's College.

Duran, E., \& Duran, B. (1995). Native American postcolonial psychology. Albany, NY: State University of New York.

Flannery, R. (1953). The Gros Ventres of Montana: Part I-Social life. Washington, DC: Catholic University of America.

Fowler, L. (1987). Shared symbols, contested meanings: Gros Ventre culture and history, 1778-1984. Ithaca, NY: Cornell University.
Gone, J. P. (1999). "We were through as Keepers of it": The "Missing Pipe Narrative" and Gros Ventre cultural identity. Ethos, 27(4), 415-440.

Gone, J. P. (2003). American Indian mental health service delivery: Persistent challenges and future prospects. In J. S. Mio \& G. Y. Iwamasa (Eds.), Culturally diverse mental health: The challenges of research and resistance (pp. 211-229). New York: Brunner-Routledge.

Gone, J. P. (2004a). Keeping culture in mind: Transforming academic training in professional psychology for Indian country. In D. A. Mihesuah \&A. Cavender Wilson (Eds.), Indigenizing the academy: Transforming scholarship and empowering communities (pp. 124-142). Lincoln, NE: University of Nebraska.

Gone, J. P. (2004b). Mental health services for Native Americans in the 21st century United States. Professional Psychology: Research and Practice, 35(1), 10-18.

Gone, J. P. (2006a). "As if reviewing his life": Bull Lodge's narrative and the mediation of self-representation. American Indian Culture and Research Journal, 30(1), 67-86.

Gone, J. P. (2006b). Mental health, wellness, and the quest for an authentic American Indian identity. In T. Witko (Eds.), Mental health care for urban Indians: Clinical insights from Native practitioners (pp. 55-80). Washington, DC: American Psychological Association.

Gone, J. P. (2006c). Research reservations: Response and responsibility in an American Indian community. American Journal of Community Psychology, 37(3-4), 333-340.

Gone, J. P. (2007a). "I came to tell you of my life": Narrative expositions of "mental health" in an American Indian community. Manuscript submitted for publication.

Gone, J. P. (2007b). Psychotherapy and traditional healing in American Indian cultural contexts: A comparison of ethnotherapeutic paradigms. Manuscript submitted for publication.

Gone, J. P. (in press a). Encountering professional psychology: Reenvisioning mental health services for Native North America. In L. J. Kirmayer \& G. Valaskakis (Eds.), Healing traditions: The mental health of Aboriginal peoples. Vancouver: University of British Columbia.

Gone, J. P. (in press b). "So I can be like a Whiteman": The cultural psychology of space and place in American Indian mental health. Culture \& Psychology.

Gone, J. P. (in press c). The Pisimweyapiy Counselling Centre: Paving the red road to wellness in Northern Manitoba. In J. B. Waldram (Ed.), Aboriginal healing in Canada: Case studies of therapeutic meaning and practice. Ottawa, Ontario: Aboriginal Healing Foundation.

Gone, J. P., \& Alcántara, C. (2006). Traditional healing and suicide prevention in Native American communities: Research and policy considerations. Unpublished report contracted by the Office of Behavioral and Social Sciences Research, National Institutes of Health (Contract No. MI-60823).

Gone, J. P., \& Alcántara, C. (in press). Identifying effective mental health interventions for American Indians and Alaska Natives: A review of the literature. Cultural Diversity \& Ethnic Minority Psychology.

Gone, J. P., Miller, P. J., \& Rappaport, J. (1999). Conceptual self as normatively oriented: The suitability of past personal narrative for the study of cultural identity. Culture \& Psychology, 5(4), 371-398

Jason L A., Keys C. B., Suarez-Balcazar Y., Taylor R. R., Davis M. I., Durlak J. A., Isenberg D. H. (Eds.) (2003). Participatory community research: Theories and methods in action. Washington, DC: American Psychological Association.

Jenkins, P. (2004). Dream catchers: How mainstream America discovered Native spirituality. Oxford: Oxford University. 
Kirmayer, L. J., Brass, G. M., \& Tait, C. L. (2000). The mental health of aboriginal peoples. Canadian Journal of Psychiatry, 45(7), 607-616.

Kirmayer, L. J., Simpson, C., \& Cargo, M. (2003). Healing traditions: Culture, community and mental health promotion with Canadian Aboriginal peoples. Australasian Psychiatry, 11(Supp), S15S23.

Kleinman A. (1995). Writing at the margin: Discourse between anthropology and medicine. Berkeley, CA: University of California.

Manson, S. M., \& Althschul, D. B. (2004). Cultural diversity series: Meeting the mental health needs of American Indians and Alaska Natives. Washington, DC: National Technical Assistance Center for State Mental Health Planning, National Association of State Mental Health Program Directors.

McMillan, D. W., \& Chavis, D. M. (1986). Sense of community: A definition and theory. Journal of Community Psychology, 14, 623.

Morrison K. M. (2000). The cosmos as intersubjective: Native American other-than-human persons. In G. Harvey (Ed.), Indigenous religions: A companion (pp. 23-36). New York: Cassell.

O’Nell, T. D. (1996). Disciplined hearts: History, identity, and depression in an American Indian community. Berkeley: University of California Press.

Pevar, S. L. (2004). The rights of Indians and Tribes: The authoritative ACLU guide to Indian and tribal rights (3rd ed.). New York: New York University.f.

Pole, N., Gone, J. P., \& Kulkarni, M. (in press). Posttraumatic Stress Disorder among ethnoracial minorities in the United States. Clinical Psychology: Science and Practice.

Rappaport, J. (1977). Community psychology: Values, research, and action. Fort Worth, TX: Holt, Rinehart, and Traveling Thunder.

Rappaport, J. (1990). Research methods and the empowerment social agenda. In P. Tolan, C. Keys, F. Chertok, \& L. Jason (Eds.), Researching community psychology: Issues of theory and method (pp. 51-63). Washington, DC: American Psychological Association.

Rappaport, J., \& Seidman, E. (2000). Handbook of community psychology. New York: Kluwer Academic/Plenum.

Rapley, M., \& Pretty, G. M. H. (1999). Playing Procrustes: The interactional production of a "psychological sense of community". Journal of Community Psychology, 27(6), 695-713.

Sarason, S. B. (1974). The psychological sense of community: Prospects for a community psychology. San Francisco: JosseyBass.

Sarason, S. B. (1986). Commentary: The emergence of a conceptual center. Journal of Community Psychology, 14, 405-407.

Serrano-Garcìa, I. (1990). Implementing research: Putting our values to work. In P. Tolan, C. Keys, F. Chertok, \& L. Jason (Eds.), Researching community psychology: Issues of theory and methods (pp. 171-182) Washington, DC: American Psychological Association.

Shweder, R. A. (1991). Thinking through cultures: Expeditions in cultural psychology. Cambridge, MA: Harvard University.

Smedley, B. D, Stith, A. Y., \& Nelson, A. R. (Eds.) (2002). Unequal treatment: Confronting racial and ethnic disparities in health care. Washington, DC: National Academy Press.
Stannard, D. E. (1992). American holocaust: Columbus and the conquest of the new world. New York: Oxford University.

Tafoya, N., \& Del Vecchio, A. (2005). Back to the future: An examination of the Native American holocaust experience. In M. McGoldrick, J. Giordana, \& N. Garcia-Preto (Eds.), Ethnicity and family therapy (3rd ed., pp. 55-63). New York: Guilford.

U.S. Census Bureau. (2002). The American Indian and Alaska Native population: 2000 (Census 2000 Brief). Washington, DC: Author. Retrieved May 25, 2002, from http://www.census.gov/prod/2002pubs/c2kbr01-15.pdf.

U.S. Commission on Civil Rights. (2004). Broken promises: Evaluating the Native American health care system (Draft Report for Commissioners' Review). Washington, DC: U.S. Commission on Civil Rights.

U.S. Department of Health and Human Services. (2001). Mental health: Culture, race, and ethnicity-A supplement to Mental health: A report of the Surgeon General. Rockville, MD: U.S. Department of Health and Human Services, Substance Abuse and Mental Health Services Administration, Center for Mental Health Services.

U.S. Department of Health and Human Services. (2005). 2005 national healthcare disparities report (AHRQ Publication No. 06-0017). Rockville, MD: U.S. Department of Health and Human Services, Agency for Healthcare Research and Quality.

U.S. Department of the Interior. (2002). Bureau of Indian Affairs. In Bureau highlights (pp. 77-85). Washington, DC: Author. Retrieved May 25, 2002, from http://www.doi.gov/budget/2003/03Hilites/BH77.pdf.

Waldram, J. B. (2004). Revenge of the windigo: The construction of the mind and mental health of North American Aboriginal peoples. Toronto: University of Toronto.

Walters, K. L., \& Simoni, J. M. (2002). Reconceptualizing Native women's health: An "indigenist" stress-coping model. American Journal of Public Health, 92(4), 520-524.

Weaver, H. N., \& Yellow Horse Brave Heart, M. (1999). Examining two facets of American Indian identity: Exposure to other cultures and the influence of historical trauma. Journal of Human Behavior in the Social Environment, 2(1-2), 19-33.

Whitbeck, L. B., Adams, G. W., Hoyt, D. R., \& Chen, X.(2004). Conceptualizing and measuring historical trauma among American Indian people. American Journal of Community Psychology, 33, 119-130.

Yellow Horse Brave Heart, M. (1999). Oyate Ptayela: Rebuilding the Lakota nation through addressing historical trauma among Lakota parents. Journal of Human Behavior in the Social Environment, 2(1/2), 109-126.

\section{Author Biography}

Joseph P. Gone is assistant professor in the Department of Psychology (Clinical Area) and the Program in American Culture (Native American Studies) at the University of Michigan in Ann Arbor. Gone received his Ph.D. in clinical and community psychology at the University of Illinois at Urbana-Champaign. His research interests include cultural psychology and American Indian mental health. He may be contacted by email at jgone@umich.edu. 